\title{
Implementation of Influenza-like illness Sentinel Surveillance in Togo
}

Issaka Maman ${ }^{*}$, Kossi Badziklou', Essoya D Landoh², Afiwa W Halatoko', Talla N Nzussouo ${ }^{3}$, Gabriel N Defang ${ }^{4}$, Tsidi A Tamekloe ${ }^{2}$, Pamela J Kennedy ${ }^{5}$, Williams Thelma ${ }^{3}$, Komlan Kossi ${ }^{1}$, Zoulkarneiri Issa ${ }^{1}$ and Abiba B Kere ${ }^{1}$

\begin{abstract}
Background: The emergence of avian influenza A/H5N1 in 2003 as well as the pandemic influenza A (H1N1) pdm09 highlighted the need to establish influenza sentinel surveillance in Togo. The Ministry of Health decided to introduce Influenza to the list of diseases with epidemic potential. By April 2010, Togo was actively involved in influenza surveillance. This study aims to describe the implementation of ILI surveillance and results obtained from April 2010 to December 2012.

Methods: Two sites were selected based on their accessibility and affordability to patients, their adequate specimen storage capacity and transportation system. Patients with ILI presenting at sentinel sites were enrolled by trained medical staff based on the World Health Organization (WHO) case definitions. Oropharyngeal and nasopharyngeal samples were collected and they were tested at the National Influenza Reference Laboratory using a U.S. Centers for Disease Control and Prevention (CDC) validated real time RT-PCR protocol. Laboratory results and epidemiological data were reported weekly and shared with all sentinel sites, Ministry of Health, Division of Epidemiology, WHO and CDC/NAMRU-3.
\end{abstract}

Results: From April 2010 to December 2012, a total of 955 samples were collected with 52\% of the study population aged between 0 and 4 years. Of the 955 samples, 236 (24.7\%) tested positive for influenza viruses; with 136 (14.2\%) positive for influenza A and 100 (10.5\%) positive for influenza B. The highest influenza positive percentage (30\%) was observed in 5-14 years old and patients aged $0-4$ and $>60$ years had the lowest percentage (20\%). Clinical symptoms such as cough and rhinorrhea were associated more with ILI patients who were positive for influenza type A than influenza type B. Influenza viruses circulated throughout the year with the positivity rate peaking around the months of January, May and again in October; corresponding respectively to the dry-dusty harmattan season and the long and then the short raining season. The pandemic A (H1N1) pdm09 was the predominantly circulating strain in 2010 while influenza B was the predominantly circulating strain in 2011 . The seasonal A/H3N2 was observed throughout 2012 year.

Conclusions: This study provides information on influenza epidemiology in the capital city of Togo.

Keywords: Influenza, Human, Sentinel surveillance, Influenza-like illness (ILI), Lomé commune

\footnotetext{
* Correspondence: mamanissaka@yahoo.fr

'National Influenza Reference Laboratory, Institut National d'Hygiène, 26 QAD

Rue Nangbeto, 01 Lomé-Sud, POBOX: 1396, Lome, Togo

Full list of author information is available at the end of the article
} 


\section{Background}

Influenza-like-illnesses (ILI) is a significant source of morbidity and mortality worldwide [1]. The World Health Organization (WHO) estimates that globally influenza accounts for between 3 and 5 million severe cases and 250.000 to 500.000 deaths annually, with most deaths occurring among elderly populations [2].

In temperate regions, ILI is reported throughout the year with a marked increase in cases recorded during winter periods [3]. However, in tropical and subtropical regions where viral transmission occurs throughout the year, the data on the burden of influenza-like-illness are limited. Nevertheless there is some evidence of a slight increase in cases during the rainy season $[4,5]$.

The emergence of new highly pathogenic influenza A/ H5N1 viruses in 2003 [6], their wide circulation in wild and domestic birds and its association with human infections which involves high mortality, has raised global concern about the risk of another influenza pandemic. The emergence of novel human pandemic influenza A (H1N1) in April 2009 [7,8] and its rapid worldwide spread has motivated the monitoring of influenza and has enhanced preparedness to counter a possible emerging pandemic. In the African Region, countries in collaboration with international partners (e.g. WHO, CDC, NAMRU-3, etc.) put efforts together to establish influenza surveillance capacities as part of the broader strategy for Integrated Disease Surveillance and Response (IDSR) [9,10]. While most countries in Asia, North America and Europe have wellestablished influenza surveillance, few such systems have been established in sub-Saharan Africa [5,11]. Influenza surveillance helps in understanding the epidemiology and impact of the disease; therefore providing information about seasonality and the groups at high risk of influenza infection. Furthermore, the identification and characterization of circulating viruses will help to provide influenza isolates for monitoring changes in viral antigens and the development of vaccines. Thus influenza surveillance provides data for pandemic influenza monitoring and planning as well as for decision-making [12-14].

In Togo, the first suspected cases of human avian influenza A/H5N1 were reported between 2007 and 2008 in the Maritime Region, a few kilometers from the capital city Lomé, which has a population of more than 2 millions. Between April and December 2009, cases of ILI were observed and were suspected to be pandemic influenza given the emergence of the novel human pandemic influenza A (H1N1) pdm09. With no ongoing influenza surveillance, our country was not yet ready to confirm and effectively monitor the severity of the disease. The lack of molecular laboratory technology to detect influenza viruses significantly reduced our ability to manage and control the pandemic. Therefore, the Ministry of
Health $(\mathrm{MoH})$ in collaboration with the Institut National d'Hygiène (INH) decided to add influenza to the list of diseases with epidemic potential to be monitored and reported through the IDSR Program. By April 2010, Togo was actively involved in ILI surveillance with the support of United State Government through the Centers for Disease Control (CDC) and the Naval Medical Research Unit-3 (NAMRU-3).

This study aims to describe the implementation of ILI surveillance and results obtained from April 2010 to December 2012.

\section{Methods}

\section{Study protocol}

The ILI surveillance system constitutes a collaborative partnership between several Togolese institutions within the Ministry of Health $(\mathrm{MoH})$. The departments involved in this surveillance are the Division of Epidemiology, the National Influenza Reference Laboratory (NIL) hosted by the Institut National d'Hygiène (INH), and the sentinel sites located at the Hôpital de Bè and Military Health Services in the capital city Lomé (Figure 1). A protocol for influenza surveillance was written with the technical support of CDC and NAMRU-3 experts.

\section{Sentinel sites selection}

The ILI sentinel surveillance sites were selected based on their accessibility and affordability to patients with low socioeconomic status, the qualifications of medical staff, adequate specimen storage capacity, and an established transportation system to the National Influenza Reference Laboratory (NIL).

The first site was Hôpital de Bè, established in April 2010 and located in District $N^{\circ} 3$. This site was chosen for its geographical location in an area of high population density and high consultation rate. This hospital hosts a pediatric unit and a general medicine ward. The second site established in December 2011, is under the management of the Military Health Services and located in District $\mathrm{N}^{\circ}$; its selection was based on the essential role of the Armed forces in case of a pandemic and their ability to serve both military and civilian populations. This military site is composed of three units and is attended by military personnel, their families as well as civilians.

The two sentinel sites are located in the capital city of Togo where approximately $20 \%$ of the country's population lives. Lomé has two rainy seasons and two dry seasons: the long rainy season (April to June) and the short rainy season (mid-September to October). The long dry season extends from December through March, while the short dry season lasts for two months (July to August). Lomé is a coastal city that borders the Atlantic Ocean to the south, Ghana to the west, Benin to the east (Figure 1) 


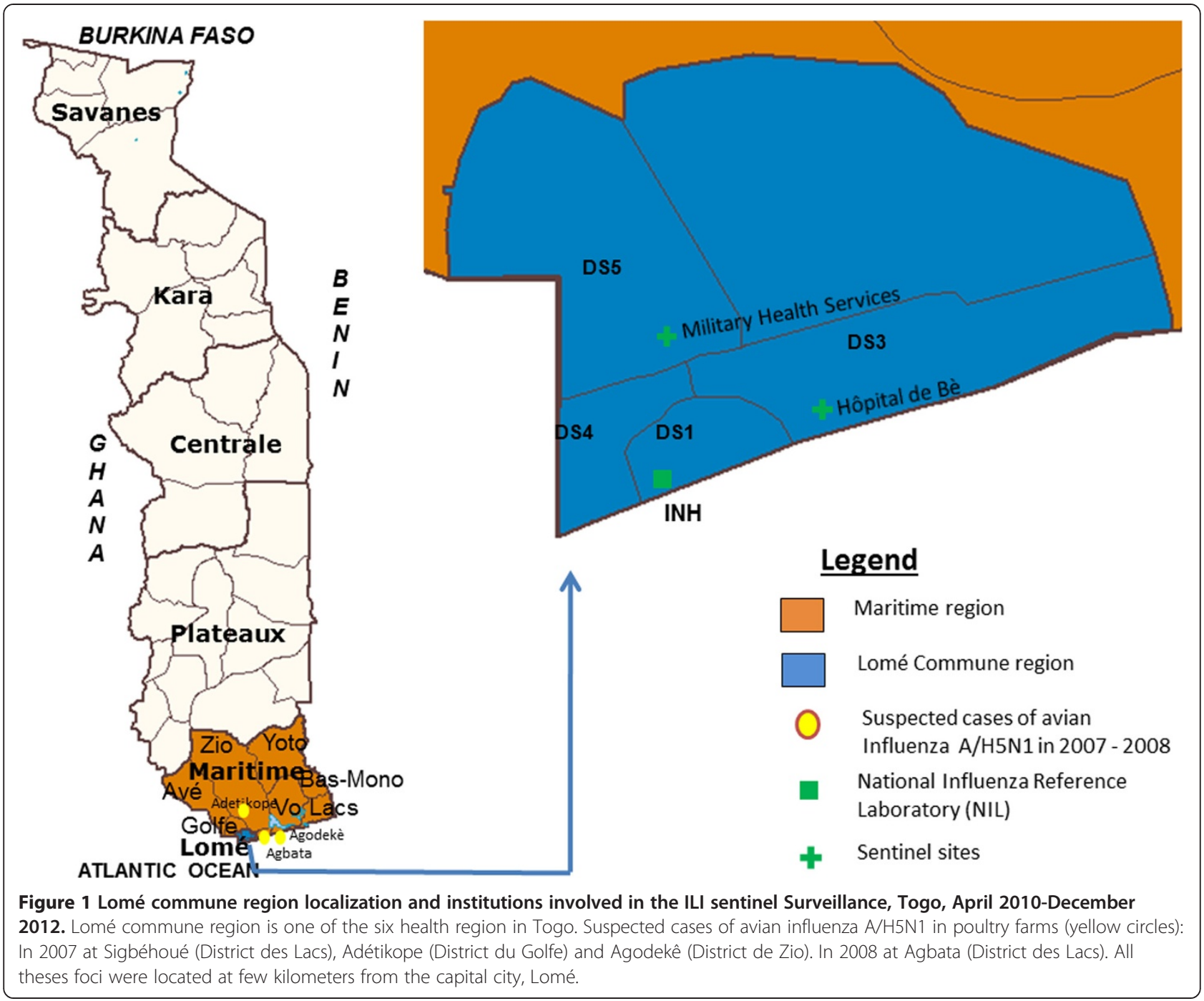

and is at the crossroad with considerable commercial exchange of goods and movements of population.

\section{Case definition and study population}

The WHO case definition [15] that was used, defined ILI as "any person with a sudden onset of fever $\left(\geq 38^{\circ} \mathrm{C}\right)$ and cough or sore throat accompanied or not by general symptoms such as myalgia, prostration, headache or malaise". This definition was used during 2010-2011 period. In 2012, the definition was changed to "any person with a sudden onset of fever $\left(\geq 38^{\circ} \mathrm{C}\right)$ or history of fever and cough or sore throat accompanied or not by general symptoms such as myalgia, prostration, headache or malaise".

At both sentinel sites, from Monday to Friday physicians enrolled the first two outpatients who met the case definition and samples were collected during consultation.

The study population included every outpatient, between April 2010 to December 2012, presenting at any of the sentinel sites and meeting the ILI case definitions regardless of age or sex and who consented to participate in the surveillance. This population represents a wide cross-section of ethnic and socioeconomic groups.

\section{Sample collection}

Samples collected were nasopharyngeal and oropharyngeal swabs and were placed in the same tube containing a viral transport medium (VTM). They were stored between 2 to $8^{\circ} \mathrm{C}$ at the bacteriology laboratory of the sentinel site prior to delivery to the NIL within 48 hours. Before samples were transported, laboratory personnel at the sentinel site conducted quality control checks of information on patients' case report forms. The NIL provides the sentinel sites with logistical and material support such as swabs, viral transportation media, cryovials, cool boxes, and ice packs. A quota of 20 samples was targeted from each sites and transported twice a week (Tuesday and Thursday) to the NIL. Review meetings with all stakeholders were organized two or three times per year as part of a strategy to 
improve the surveillance system by identifying strengths and areas of concern during these meetings.

\section{Data collection and management}

Socio-demographic (age, sex, date of birth, residential area, travel history) and clinical (date of onset, date of consultation, previous treatment, vaccination status, co-morbidities) data were collected from all patients using a case report form (CRF) during consultation. Epidemiological data were stored in a single database with laboratory data using a single identification number for each patient. Each week, NIL provided reports on the distribution of total samples collected, as well as on the number of confirmed influenza cases to the $\mathrm{MoH}$, to the sentinel sites, WHO FluNet, CDC, and NAMRU-3.

\section{Laboratory analysis}

Samples collected were analyzed at the National Reference Influenza laboratory at INH. From every sample, three aliquots were made, two of which were stored at $-80^{\circ} \mathrm{C}$ for external quality control and further analysis (if not subtyped) at NAMRU-3 in Cairo, Egypt. The other one was kept between 2 to $4^{\circ} \mathrm{C}$ for RNA extraction followed by influenza virus detection by real time RTPCR within 72 hours after sample reception.

\section{RNA extraction and real time RT-PCR}

For the testing of influenza viruses, RNA extraction was performed from $140 \mu \mathrm{l}$ of naso and/or oro-pharyngeal cells contained in the VTM by using a QIAmp Viral RNA Mini Kit (Qiagen) following the manufacturer's protocol. For detection and typing, it was run on an ABI 7300 machine, the real time RT-PCR using the Ambion enzyme AgPath one-step (Ambion, Applied Biosystems) that amplifies Influenza A and B. The U.S. CDC provided the protocol used to detect influenza viruses [16]. In order to determine the quality of the sample, the presence of human ribo-nucleoprotein (RNP) was assessed for each specimen tested.

\section{Statistical analysis}

Socio-demographic and clinical epidemiological data were entered into a database created using Epi-Info Software version 3.5. Data analysis was conducted using SPSS software version 16.0 (SPSS Inc., Chicago, IL). Student t-test was used for comparison of mean age and the Pearson Chi-square or Fisher exact test to compare laboratory results by age groups and clinical symptoms.

\section{Ethical considerations}

The protocol was approved by the $\mathrm{MoH}$ as part of the monitoring of diseases with epidemic potential and therefore did not require ethical review. Verbal consent was obtained from all patients.

\section{Results}

\section{Characteristics of population}

A total of 955 patients were enrolled in this study. Seven hundred and twenty seven (76\%) patients were enrolled from the Hôpital de Bè and 228 (24\%) from the Military Health Service site (Table 1). There was no significant difference in the proportion of females compared to males enrolled in this study $(49.9 \%$ vs. $50.1 \%$; $\mathrm{p}=0.37)$, and the gender distribution at the two sites was similar. Most of patients (65\%) were under 15 years of age, while less than $6 \%$ were 45 years or older. Patients who presented at the Hôpital de Bè were significantly older (mean age $=17.1$ years) compared to those who were seen at the Military Health Service (mean age $=10.6$ years with $71 \%$ of patients aged less than 5 years $)(p=0.0001)$. Approximately $2 \%$ of the patients reported having received influenza vaccination within the last year.

\section{Laboratory results}

Of the samples collected for ILI surveillance, 236 (24.7\%) tested positive for influenza viruses. Of these, 136 (14.2\%) tested positive for influenza A virus and 100 (10.5\%) for influenza B virus (Table 2). The proportion of influenza positive cases ranged from $32 \%$ in 2010 to $22.5 \%$ in 2012 . Type and subtype varied by year, with influenza A being predominant in 2010 and 2012, and influenza B predominant in 2011. Of the influenza A subtypes, pandemic A (H1N1) pdm09 was predominant in 2010 while seasonal A/H3N2 was predominant in 2012 (Table 2). The proportion of influenza positive cases varied between different age groups with a higher proportion of influenza A detected in the 15-29 year-old group (20\%) than other age groups ( $p=0.01$; Table 3 ). Significantly, the pandemic influenza A (H1N1) pdm09 was more often detected in patients aged 5-14 $(\mathrm{p}=0.003)$ and $15-29(\mathrm{p}=0.03)$ years than in other age groups. Seasonal A/H3N2 was predominant in patients aged $30-44$ years $(15 \% ; \mathrm{p}=0.0003)$ and was the only influenza A subtype detected among patients who were 60 years or older.

\section{Temporal distribution}

ILI was observed throughout every year with irregular peak activity occurring twice annually during the months of; May and November in 2010; May and October in 2011; April/August, October in 2012 (Figure 2). However, the number of patients/samples enrolled was not consistent. Influenza A virus was detected predominantly in 2010 and correlated with the ILI peak. The first cases of pandemic influenza A (H1N1) pdm09 were only confirmed in May. During the ILI peak, the influenza positivity rate was $26 \%$ in May and 30\% in November with the pandemic influenza strain, the most subtype detected. The pandemic virus remained predominant between October 2010 and April 2011 (Figure 2). During the ILI peaks in 2011, the 
Table 1 Characteristics of ILI patients enrolled into the influenza sentinel surveillance system, Togo, April 2010-December 2012

\begin{tabular}{|c|c|c|c|}
\hline & $\begin{array}{l}\text { Hôpital } \\
\text { de Bè n (\%) }\end{array}$ & $\begin{array}{l}\text { Military health } \\
\text { Services } \mathrm{n}(\%)\end{array}$ & $\begin{array}{l}\text { Total } \\
\mathrm{n}(\%)\end{array}$ \\
\hline Number of subjects enrolled & 228 & 955 & 727 \\
\hline \multicolumn{4}{|l|}{ Sex } \\
\hline Female & $369(50,8)$ & $108(47,4)$ & $477(49,9)$ \\
\hline Male & $358(49,2)$ & $120(52,6)$ & $478(50,1)$ \\
\hline \multicolumn{4}{|l|}{ Age } \\
\hline Mean \pm Std (yrs) & $10,6 \pm 13,2$ & $15,7 \pm 16,5$ & $17,1 \pm 17,05$ \\
\hline Median (range in yrs) & 3 [1 mo-58] & 6 [1mo-90] & 8 [1mo-90] \\
\hline $0-4$ & $330(45,3)$ & $162(71,0)$ & $492(51,5)$ \\
\hline $5-14$ & $114(15,7)$ & $19(8,3)$ & $133(13,9)$ \\
\hline $15-29$ & $122(16,8)$ & $25(10,9)$ & $147(15,4)$ \\
\hline $30-44$ & $114(15,7)$ & $19(8,3)$ & $133(13,9)$ \\
\hline $45-59$ & $37(5,1)$ & $3(1,3)$ & $40(4,2)$ \\
\hline$\geq 60$ & $10(1,4)$ & $0(0,0)$ & $10(1,0)$ \\
\hline Vaccination history (Self reported) & $3(1,3)$ & $17(1,8)$ & $14(1,9)$ \\
\hline
\end{tabular}

Std $=$ Standard $\mathrm{mo}=$ month yrs $=$ years .

influenza positive rate ranged from $20 \%$ to $60 \%$ with the predominance of influenza B virus activity in May representing $93 \%$ of all virus detected (28/30). The second peak was correlated to the seasonal influenza A/H3N2 activity in October with $80 \%$ of viruses detected (8/10). From October 2011, there was a co-circulation of influenza type $A$ and type B with low activity of pandemic strain until September 2012 while the seasonal influenza A/H3N2 was detected throughout the year 2012 .

\section{Clinical manifestations}

Fever (85\%), cough (87\%), and rhinorrhea (76\%) were the major symptoms for all age groups although sore throat (38\%) and headaches (14\%) were also recorded (Table 4). ILI patients who tested positive for influenza were more likely to present with cough $(\mathrm{p}=0.004)$ and headaches $(\mathrm{p}=0.03)$ but were less likely to present with difficulty breathing $(\mathrm{p}=0.02)$ compared to those who tested negative for the influenza virus. Among symptoms, only cough was more common in patients testing positive for influenza $A$ than those who tested positive for influenza $B$ $(\mathrm{p}=0.003)$. Rhinorrhea was more common in patients with seasonal $\mathrm{A} / \mathrm{H} 3 \mathrm{~N} 2$ than in those with pandemic influenza A $(\mathrm{H} 1 \mathrm{~N} 1)$ pdm09 $(\mathrm{p}=0.0004)$.

\section{Discussion}

Due to the lack of ILI surveillance in Togo, there was no information about the epidemiology of ILI or influenza viruses until 2010. The first samples collected were processed in May 2010 and the presence of pandemic influenza $\mathrm{A}(\mathrm{H} 1 \mathrm{~N} 1)$ pdm09 virus was confirmed in Togo one year after the novel pandemic influenza occurred in Mexico (April 2009). This is the first report that describes the epidemiology of influenza in Togo using data from the ILI sentinel surveillance system. During the two and half year period of ILI sentinel surveillance, influenza viruses were detected in 236 (25\%) of 955 samples. The average percentage positive in this study was higher than the positivity rate observed in 15 other African countries between 2006 and 2010 [17]. However, during the same timeframe, other countries in the temperate climate region: Madagascar (40\%), Morocco

Table 2 Distribution of number of samples collected and influenza positivity rate by year, Togo,

April 2010-December 2012

\begin{tabular}{|c|c|c|c|c|c|c|c|}
\hline \multirow[b]{2}{*}{ Years } & \multirow[b]{2}{*}{ Total $n$} & \multirow[b]{2}{*}{$\begin{array}{l}\text { Positive cases } \\
\text { n (\%) }\end{array}$} & \multirow[b]{2}{*}{$\begin{array}{l}\text { Influenza B } \\
\text { n (\%) }\end{array}$} & \multirow[b]{2}{*}{$\begin{array}{l}\text { Influenza A } \\
\text { n (\%) }\end{array}$} & \multicolumn{3}{|c|}{ Subtypes of influenza A } \\
\hline & & & & & $\begin{array}{l}\text { A/H3N2 } \\
\text { n (\%) }\end{array}$ & $\begin{array}{l}\text { A(H1N1) pdm09 } \\
\text { n (\%) }\end{array}$ & $\begin{array}{l}\text { A/Unsubtypeable } \\
\text { n (\%) }\end{array}$ \\
\hline April to December 2010 & 87 & $28(32.2)$ & $3(3.4)$ & $25(28.7)$ & $3(3.4)$ & $21(24.1)$ & $1(1.1)$ \\
\hline 2011 & 335 & $88(26.3)$ & 49 (14.6) & $39(11.6)$ & $17(5.1)$ & $20(5.9)$ & $2(0.6)$ \\
\hline 2012 & 533 & $120(22.5)$ & $48(9.0)$ & $72(13.5)$ & $51(9.5)$ & $21(3.9)$ & $0(0.0)$ \\
\hline Total & 955 & $236(24.7)$ & $100(10.5)$ & $136(14.2)$ & $71(7.4)$ & $62(6.5)$ & $3(0.3)$ \\
\hline
\end{tabular}


Table 3 Distribution of influenza viruses confirmed and ILI patients by age, Togo, April 2010-December 2012

\begin{tabular}{|c|c|c|c|c|c|c|c|c|}
\hline \multirow[b]{2}{*}{ Age groups (Years) } & \multirow[b]{2}{*}{ Total $n$} & \multirow[b]{2}{*}{$\begin{array}{l}\text { Negatives } \\
\mathrm{n}(\%)\end{array}$} & \multirow[b]{2}{*}{$\begin{array}{l}\text { Positive cases } \\
\text { n (\%) }\end{array}$} & \multirow[b]{2}{*}{$\begin{array}{l}\text { Influenza B } \\
\mathrm{n}(\%)\end{array}$} & \multirow[b]{2}{*}{$\begin{array}{l}\text { Influenza A } \\
\mathrm{n}(\%)\end{array}$} & \multicolumn{3}{|c|}{ Subtypes of influenza A } \\
\hline & & & & & & $\begin{array}{l}\text { A/H3N2 } \\
\text { n (\%) }\end{array}$ & $\begin{array}{l}\text { A(H1N1) pdm09 } \\
\text { n (\%) }\end{array}$ & $\begin{array}{l}\text { A/Unsubtypeable } \\
\text { n (\%) }\end{array}$ \\
\hline $0-4$ & 492 & $392(79.7)$ & $100(20.3)$ & $48(9.7)$ & $52(10.6)$ & $29(5.9)$ & $21(4.3)$ & $2(0.4)$ \\
\hline $5-14$ & 133 & $92(69.2)$ & $41(30.8)$ & $20(15.0)$ & $21(15.8)$ & $5(3.7)$ & $16(12.0)$ & $0(0.0)$ \\
\hline $15-29$ & 147 & $107(72.8)$ & $40(27.2)$ & $10(6.8)$ & $30(20.4)$ & $11(7.5)$ & $19(12.9)$ & $0(0.0)$ \\
\hline $30-44$ & 133 & $92(69.2)$ & $41(30.8)$ & $17(12.8)$ & $24(18.0)$ & $20(15.0)$ & $3(2.2)$ & $1(0.7)$ \\
\hline $45-59$ & 40 & $28(70.0)$ & $12(30.0)$ & $5(12.5)$ & $7(17.5)$ & $4(10.0)$ & $3(7.5)$ & $0(0.0)$ \\
\hline$\geq 60$ & 10 & $8(80.0)$ & $2(20.0)$ & $0(0.0)$ & $2(20.0)$ & $2(20.0)$ & $0(0.0)$ & $0(0.0)$ \\
\hline Total & 955 & $719(75.3)$ & $236(24.7)$ & $100(10.5)$ & $136(14.2)$ & $71(7.4)$ & $62(6.5)$ & $03(0.3)$ \\
\hline
\end{tabular}

(27\%) and South Africa (40\%) did show a high positivity rate as well as Peru (35\%; 2006-2008) [18].

There are several reasons to explain the difference in the percentage positive observed between countries including the temporal distribution of these viruses, the sample collection method, the number of samples collected and the geographical distribution of sentinel sites. Most of our data includes post pandemic influenza A (H1N1) pdm09; this is a different picture compared to other African countries (2006-2010) and to the South American region. The sample collection method was different from one country to another. In our study, we used two swabs (one oro-pharyngeal and one nasopharyngeal) for each enrolled patient and put both swabs in the same cryotube, thereby increasing the viral load and enhancing RT-PCR detection while in some other countries samples were collected either with nasopharyngeal [19] or oro-pharyngeal swab only [18,20]. In addition, the number of samples tested in most of the other countries was quite high compared to our sample numbers and they were collected from many sites ranging from only 3 to as many as 22 . We only used two sentinel sites as our catchment area. The influenza positivity rate varied by year with the highest rate obtained in 2010. Since the number of samples collected during this year was very low (87 samples) than the two subsequent years, the rate could be influenced. Nevertheless, our percentage positive was similar to that of Ghana and Rwanda in Africa [17] and that of Taiwan [21], but at different periods of time.

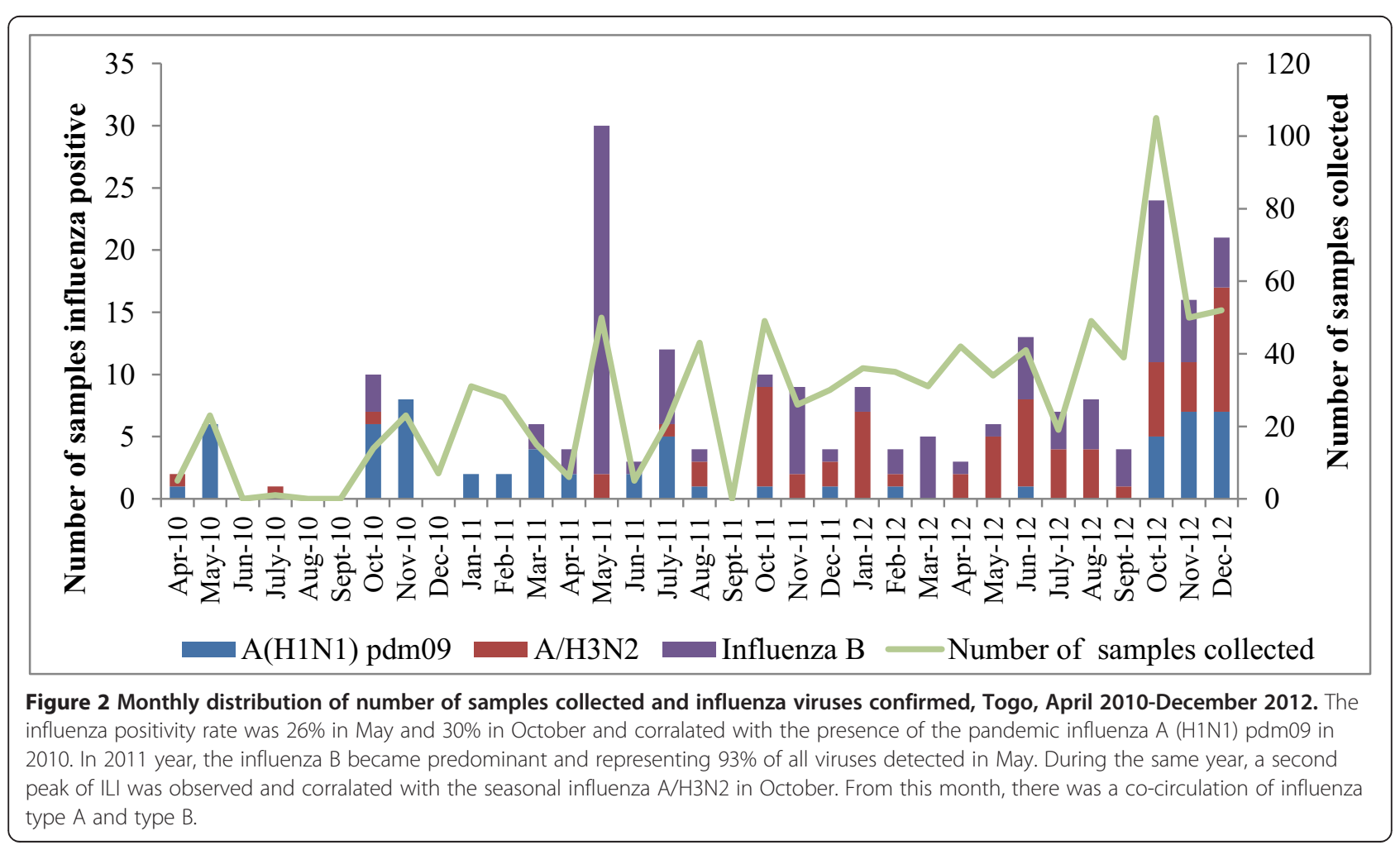


Table 4 Clinical symptoms among patients with influenza-like illness, by influenza virus laboratory test findings, Togo, April 2010-December 2012

\begin{tabular}{llllllllll}
\hline & $\begin{array}{l}\text { Total } \\
\mathbf{n}(\%)\end{array}$ & $\begin{array}{l}\text { Negatives } \\
\mathbf{n}(\%)\end{array}$ & $\begin{array}{l}\text { Positive cases } \\
\mathbf{n}(\%)\end{array}$ & $\begin{array}{l}\text { Influenza B } \\
\mathbf{n}(\%)\end{array}$ & $\begin{array}{l}\text { Influenza A } \\
\mathbf{n}(\%)\end{array}$ & $\begin{array}{l}\text { A/H3N2 } \\
\mathbf{n}(\%)\end{array}$ & $\begin{array}{l}\mathbf{A}(\mathbf{H} 1 \mathbf{N 1}) \text { pdm09 } \\
\mathbf{n}(\%)\end{array}$ & $\begin{array}{l}\text { A/Unsubtypeable } \\
\mathbf{n}(\%)\end{array}$ \\
\hline Clinical symptoms & & & & & & & & & \\
Fever & $813(85.1)$ & $614(85.3)$ & $199(84.3)$ & $88(88.0)$ & $111(81.6)$ & $59(83.1)$ & $49(790.0)$ & $3(100)$ \\
Cough & $834(87.3)$ & $615(85.5)$ & $219(92.8)$ & $87(87.0)$ & $132(97.0)$ & $68(95.8)$ & $61(98.4)$ & $3(100)$ \\
rhinorrhea & $725(75.9)$ & $541(75.2)$ & $184(78.0)$ & $80(80.0)$ & $104(76.4)$ & $63(88.7)$ & $39(62.9)$ & $2(66.7)$ \\
Sore throat & $367(38.4)$ & $265(36.8)$ & $102(43.2)$ & $47(47.0)$ & $55(40.4)$ & $24(33.8)$ & $28(45.2)$ & $3(100)$ \\
Headache & $141(14.8)$ & $96(13.3)$ & $45(19.1)$ & $15(15.0)$ & $30(22.0)$ & $18(25.3)$ & $12(19.3)$ & $0(0.0)$ \\
Difficulty of breath & $175(18.3)$ & $144(20.8)$ & $31(13.1)$ & $14(14.0)$ & $17(12.5)$ & $11(15.5)$ & $6(9.8)$ & 0 & $0(0.0)$ \\
Total & $\mathbf{9 5 5}$ & $\mathbf{7 1 9 ( 7 5 . 3 )}$ & $\mathbf{2 3 6 ( 2 4 . 7 )}$ & $\mathbf{1 0 0 ( 1 0 . 5 )}$ & $\mathbf{1 3 6 ( 1 4 . 2 )}$ & $\mathbf{7 1 ( 7 . 4 )}$ & $\mathbf{6 2 ( 6 . 5 )}$ & $\mathbf{3 ( 0 . 3 )}$ \\
\hline
\end{tabular}

Influenza A was predominant in 2010 with pandemic influenza A (H1N1) pdm 09 in our study; this observation was similar to that of other countries in West Africa [17]. However, in 2010, the situation was different in other subregions with predominance of influenza $\mathrm{B}$ in Central/South and North Africa [17,22] and seasonal influenza A/H3N2 in East Africa [17]. This difference could be explained by the fact that circulation of pandemic influenza A (H1N1) pdm09 was delayed in West Africa and occurred one year after it was predominantly circulating in other African subregions $[17,23]$. While two years is not sufficient time for an adequate description of the seasonality of influenza virus transmission, we did observe trends in the Lomé commune region. The influenza $B$ virus showed a peak activity during the rainy seasons (May and October) and the pandemic influenza A (H1N1) pdm09 was more frequent during the long dry season while the seasonal A/H3N2 was detected across both seasons. Although the seasonality of influenza viruses in African countries is not yet clear, we observed that our trends were similar with the influenza peaks, which have often been associated with the rainy season activity in other tropical countries [24-26].

In our study, Influenza cases were highest (30\%) in the 5-14 year age group but also high among other age groups, with lowest percent positive (20.3\%) among $0-4$ and $>60$ years $(20.0 \%)$. This distribution is consistent with the observation in the study conducted in 15 countries of Africa during 2006 to 2010 and in Peru [17,18,20] in which young children and adults were shown to have the highest influenza viral disease. Contrary to our study, a study from Venezuela [27] showed higher detection rates in $0-4$ year olds. The percentage positive of influenza A was significantly higher in ILI patients in the 15-29 age groups. Therefore, we found that pandemic influenza A (H1N1) pdm09 was detected significantly among 5-29 years old. This finding is consistent with other studies in the African region [17,22,28] that have found that pandemic influenza A (H1N1) pdm09 is most commonly identified in school-age children and young adults. While pandemic influenza A (H1N1) pdm09 appeared more often in older children, seasonal influenza A/H3N2 appeared more likely to infect adults in the 30-44 year-age category. Our finding was similar to the observation from a study conducted in Peru [18], where the author found that the seasonal influenza $\mathrm{A} / \mathrm{H} 3 \mathrm{~N} 2$ virus was detected with adults of 45 to 59 years. In conclusion, our results are consistent with studies from Africa and South American regions which observed that seasonal influenza A/H3N2 affected a wide range of age groups with predominantly 30 to 60 years old while the pandemic influenza A (H1N1) pdm09 and influenza B virus infections occurred more frequently among older children and young adults.

We observed that clinical symptoms were associated with influenza viruses. The influenza type A was more frequently detected than type $\mathrm{B}$ in patients presenting with cough and rhinorrhea. This result is consistent with the observation of a study from Venezuela [27]. In contrast with this study were pandemic influenza A (H1N1) pdm09 was associated with ILI patients with cough, our study showed that ILI patients with rhinorrhea were associated with seasonal A/H3N2.

Our study had some limitations. Our data were collected only from 2 sites in an urban area in the capital city of Togo and could not be generalized to the population. The percent influenza positivity and age distribution of positive cases were influenced by the low number of samples collected which may be attributable to the non availability of a physician to collect nasal and orpharyngeal swabs. The low number of samples may have also contributed to the high positivity rate. In addition, this low proportion may not be representative to better describe the distribution of influenza cases in the age groups. Physician time limitations were due to the time consumption and their workload (number of patients viewed in consultation at the outpatients' department). Children were over-represented in this study thus introducing a bias, as the number of adults was not comparable to children under 5 years old. Some possible reasons to explain this bias include the fact that the Military Health Service has three units but only the 
family health care center was functional when added as a site in December 2011. Because this unit is a pediatric health center, the high number of children enrolled from this site can account for the observed figures. At the Hôpital de Bè site, we observed that many patients, mostly adults were not enrolled as ILI patients due to the lack of recorded fever $\left(\geq 38^{\circ} \mathrm{C}\right)$, suggesting that we should be considering history of fever as one of the enrollment criteria for ILI. This study focused exclusively on outpatients thus limiting our ability to examine the severity of the influenza viruses in hospitalized cases. Since our influenza surveillance system had challenges in collecting samples of severe acute respiratory infection (SARI) and the lack of data on hospitalizations with patient follow-up we excluded discussions on SARI from this study. To improve our influenza surveillance system, it will be necessary to expand the system in other regions by including SARI surveillance for severe disease to give a complete picture of influenza burden and epidemiology in our country.

\section{Conclusions}

These data provided information on the epidemiology of influenza in the Lomé commune region in the capital city of Togo. Some efforts are needed to allow better understanding of influenza burden and epidemiology by expanding sentinel sites in other regions and including SARI surveillance. Future studies will also be focused on identifying the etiologic agents for the $75 \%$ of ILI cases that were negative for influenza viruses. Retrospective analyses of these stored samples will be necessary to identify other respiratory viruses circulating, including respiratory syncytial virus (RSV), coronaviruses, Human Metapneumovirus (HMPV) and rhinoviruses.

\section{Abbreviations \\ ILI: Influenza-like illness; WHO: World Health Organization; ISDR: Integrated Disease Surveillance and Response; INH: Institut National d'Hygiène; NIL: National Influenza Laboratory; CDC: Centers for Disease Control and Prevention; NAMRU-3: Naval Medical Research Unit 3.}

\section{Competing interests}

The authors have declared that no competing interests exist.

\begin{abstract}
Authors' contributions
IM contributed to the study design, statistical analyses of data and wrote the paper. KB and EDL contributed to the study design, interpreted analysis and review the manuscript. AWH and TAT contributed in the study design and review the manuscript. TNN, GND, WT and PJK provide technical advice for study protocol, methodology, revised critically the manuscript for important scientific content and have given final approval for the version to be published. ZI and KK were involved in literature review and revising the manuscript. ABK contributed to the facilitation of the project, participated in its design, coordination and review the paper. All authors read and approved the final manuscript.
\end{abstract}

\section{Acknowledgements}

We would like to thank all sentinel staff at the Hôpital de Bè and the Military Health services for their essential role in the ILI sentinel surveillance. We are grateful to the Ministry of Health and the Division of Epidemiology for their support and coordination. We would like also express our sincere thanks to the team of the National Influenza Reference Laboratory for their efforts in collecting samples, clinical data and detection by RT-PCR of influenza viruses. We wish to thank Mr Koffi Akolly, Field Epidemiologist for designing the map of the Figure 1. The influenza sentinel surveillance was successful established with the technical and financial support of CDC and NAMRU-3. We are grateful also to CDC reviewers for their precious analyses and revision of this paper prior it's submission for publication.

\section{Author details}

'National Influenza Reference Laboratory, Institut National d'Hygiène, 26 QAD Rue Nangbeto, 01 Lomé-Sud, POBOX: 1396, Lome, Togo. ${ }^{2}$ Division de I'Epidémiologie, Ministry of Health, Lomé, Togo. ${ }^{3}$ Influenza Division, U.S. Centers for Disease Control and Prevention, Atlanta, GA, USA. ${ }^{4}$ Virology Department, U.S. Naval Medical Research Unit No 3, Cairo, Egypt. ${ }^{5}$ McKing Consulting, Influenza Division, U.S. Centers for Disease Control and Prevention, Atlanta, GA, USA.

Received: 25 January 2014 Accepted: 16 September 2014 Published: 20 September 2014

\section{References}

1. WHO: The global burden of disease: 2004 update. 2004 [http://whqlibdoc. who.int/publications/2008/9789241563710_eng.pdf]

2. WHO: Influenza Fact Sheet Available. 2007 [http://www.who.int/mediacentre/ factsheets/fs211/en. Accessed 2007 Oct 30].

3. Simonsen $L$ : The global impact of influenza on morbidity and mortality. Vaccine 1999, 17:S3-S10.

4. Moura FE, Perdigão $A C$, Siqueira MM: Seasonality of influenza in the tropics: a distinct pattern in northeastern Brazil. Am J Trop Med Hyg 2009, 81(1):180-183. PMid: 19556586.

5. Shek LP, Lee BW: Epidemiology and seasonality of respiratory tract virus infections in the tropics. Paediatr Respir Rev 2003, 4:105-111.

6. WHO: Affected areas with confirmed cases of H5N1 avian influenza. 2012 [http://www.who.int/influenza/human_animal_interface/

EN_GIP_20121217CumulativeNumberH5N1cases.pdf. Accessed 13 September 2012].

7. WHO: Pandemic (H1N1). 2009 [http://www.who.int/csr/don/2010_08_06/en/ index.html (Accessed 15 October 2012)].

8. Archer BN, Cohen C, Naidoo D, Thomas J, Makunga C: Interim Report on Pandemic H1N1 Influenza Virus Infections in South Africa, April to October 2009: Epidemiology and Factors Associated with Fatal Cases. Euro Surveill 2009, 2009(14):11-15.

9. Robert FB, Abdulsalami N, Mark A, Kariuki N, John V: Preparedness for highly pathogenic avian influenza pandemic in Africa. Emerg Infect Dis 2007, 13:1453-8

10. WHO Regional Office for Africa: Integrated disease surveillance in the African region: a regional strategy for communicable diseases 1999-2003; 2003 [http://www.afro.who.int/csr/ids/publications/ids.pdf]

11. Katz MA, Shoub BD, Heraud JM, Breiman RF: Influenza in Africa: Uncovering the Epidemiology. J Infect Dis 2012, 206(Suppl 1):S1-4.

12. Hilleman MR: Realities and enigmas of human viral influenza: pathogenesis, epidemiology and control. Vaccine 2002, 20(25-26):3068-3087.

13. WHO: Recommended composition of influenza virus vaccines for use in the, northern hemisphere influenza season. Wkly Epidemiol Rec 2011 2011, 10(86):81-92. [http://www.who.int/wer]

14. WHO: Recommended composition of influenza virus vaccines for use in the 2013 southern hemisphere influenza season. Wkly Epidemiol Rec 2012, 41(87):389-400.

15. WHO: Global Influenza Surveillance Network (GISN). Manual for the laboratory diagnosis and virological surveillance of influenza: 2011. [http://www.who. int/influenza/resources/documents/INFSURVMANUAL.pdf]

16. WHO: CDC protocol of real time RT-PCR for detection and characterization influenza 2009 A (H1N1) pdm virus. April 2009. 2009. [http://www.who.int/csr/ resources/publications/swineflu/CDCRealtimeRTPCR_SwineH1Assay2009_20090430.pdf]

17. Radin JM, Katz MA, Stefano T, Nzussouo TN, Richard D, Duque J, Adebayo A, Adjabeng MJ, Ampofo WK, Ayele W, Bakamutumaho B, Barakat A, Cohen AL, Cohen C, Dalhatu IT, Coulibaly D, Dueger E, Francisco M, Heraud J-M, Daddi J, Kabanda A, Kadjo H, Kandeel A, Shamamba SKB, Kasolo F, 
Kronmann KC, Liwewe MLM, Lutwama JJ: Influenza Surveillance in 15 countries in Africa, 2006-2010. J Infect Dis 2012, 206(Suppl):S14-21.

18. Laguna-Torres VA, Gomez J, Ocana V, Aguilar P, Saldarriaga T, Chavez E, Perez J, Zamalloa H, Forshey B, Paz I, Gomez E, Roel O, Chauca G, Ortiz E, Villaran M, Vilcarromero S, Rocha C, Chincha O, Jimenez G, Villanueva M, Pozo E, Aspajo J, Kochel T: Influenza-like illness sentinel surveillance in Peru. PLoS One 2009, 4(7):e6118.

19. Clayton OO, Njeru R, Kazungu S, Achilla R, Bulimo W, Welch SR, Cane PA, Gunson RN, Hammitt LL, Scott AGJ, Berkley JA, Nokes DJ: Influenza Surveillance Among Children With Pneumonia Admitted to a District Hospital in Coastal Kenya, 2007-2010. J Infect Dis 2012, 206(S1):61-7.

20. Workenesh A, Gelila D, Woubayehu K, Zemelak E, Afework A, Amare B, Cox CM, Daddi J: Challenges of Establishing Routine Influenza Sentinel Surveillance in Ethiopia, 2008-2010. J Infect Dis 2012, 206(S1):S41-5.

21. Chuang J-H, Huang AS, Huang W-T, Liu M-T, Chou J-H, Chang F-Y, Chiu W-T: Nationwide Surveillance of Influenza during the Pandemic (2009-10) and Post-Pandemic (2010-11) Periods in Taiwan. Plos one 2012, 7(4):e36120.

22. Tamfum JJM, Nkwembe E, Shamamba SKB, Bankoshi F, llunga BK, Katz KA, Cohen AL, Kabamba J, Wemankoy EO: Sentinel Surveillance for Influenza-like illness, severe acute respiratory illness and Laboratory-Confirmed influenza in Kinshasa, Democratic Republic of Congo, 2009-2011. J Infect Dis 2012, 206(Suppl):S36-40.

23. Ndahwouh Talla N, Michalove J, Ousmane MD, Njouom R, Lourdes Monteiro M, Kadjo H, Manoncourt S, Amankwa J, Koivogui L, Sow S, Elkory MB, Collard J-M, Dalhatu I, Mbayame NN, Lafond K, Moniz F, Coulibaly D, Kronman KC, Oyofo BA, AmpofoW K, Boubou T, Bara AO, Jusot J-F, Ekanem E, Diène Sarr F, Hwang I, Cornelius C, Coker B, Stephen L, Richard D: Delayed 2009 Pandemic Influenza A Virus Subtype H1N1 Circulation in West Africa, May 2009-April 2010. J Infect Dis 2009, 206(Suppl 1):S106-112.

24. Dosseh A, Ndiaye K, Spiegel A, Sagna M, Mathiot C: Epidemiological and virological influenza survey in Dakar, Senegal: 1996-1998. Am J Trop Med Hyg 2000, 62:639-43.

25. Zaman RU, Alamgir AS, Rahman M: Influenza in outpatient ILI case-patients in national hospital-based surveillance, Bangladesh, 2007-2008. PLoS One 2009, 4:e8452.

26. Alonso WJ, Viboud C, Simonsen L, Hirano EW, Daufenbach LZ, Miller MA: Seasonality of influenza in Brazil: a traveling wave from the Amazon to the subtropics. Am J Epidemiol 2007, 165:1434-42.

27. Comach G, Teneza-Mora N, Kochel TJ, Espino C, Sierra G, Camacho DE, Laguna-Torres VA, Garcia J, Chauca G, Gamero ME, Sovero M, Bordones S, Villalobos I, Melchor A, Halsey ES: Sentinel Surveillance of Influenza-Like Illness in Two Hospitals in Maracay, Venezuela: 2006-2010. Plos one 2012, 7(9):e44511.

28. Dalhatu IT, Medina-Marino A, OlsenS J, Hwang I, Gubio AB, Ekanem EE, Coker EBA, Akpan H, Adedeji A: Influenza Viruses in Nigeria, Results From the First 17 Months of a National Influenza Sentinel Surveillance System. $J$ Infect Dis 2009-2010, 206(Suppl 1):S121-135.

doi:10.1186/1471-2458-14-981

Cite this article as: Maman et al:: Implementation of Influenza-like illness Sentinel Surveillance in Togo. BMC Public Health 2014 14:981.

\section{Submit your next manuscript to BioMed Central and take full advantage of:}

- Convenient online submission

- Thorough peer review

- No space constraints or color figure charges

- Immediate publication on acceptance

- Inclusion in PubMed, CAS, Scopus and Google Scholar

- Research which is freely available for redistribution
C Biomed Central 